\title{
Ethnic differences in the association between waist-to-height ratio and albumin-creatinine ratio: the observational SUNSET study
}

\author{
Irene GM van Valkengoed ${ }^{1 *}$, Charles Agyemang ${ }^{1}$, Ray T Krediet $^{2}$ and Karien Stronks ${ }^{1}$
}

\begin{abstract}
Background: Ethnic differences in the association between central obesity and raised albumin-creatinine ratio (ACR) have not been investigated. Our aim was to determine whether the association between central obesity, defined by the waist-to-height ratio (WHtR), and ACR differed between subjects of Hindustani-Surinamese, AfricanSurinamese and Dutch origin.

Methods: In total, 334 Hindustani-Surinamese ( South Asian), 589 African-Surinamese ( African), and 493 Dutch ( European) men and women, aged 35-60 years, randomly selected from the municipal register of Amsterdam, participated in an interview and physical examination.

We calculated the WHtR by dividing the waist circumference by height and the log ACR (logACR, log $\mathrm{mg} / \mathrm{mmol}$ ) by log-transforming the albumin concentration by the creatinine concentration in urine. The association between WHtR and $\log A C R$ was studied in the total population and stratified by ethnicity. We also tested for interaction.

Results: In the total population, a higher WHtR was associated with a higher logACR, after adjustment for sex, age, and smoking, body mass index and the presence of type 2 diabetes or hypertension. Among the HindustaniSurinamese, the adjusted association between WHtR and logACR appeared somewhat stronger than among the other ethnic groups: for every 0.1 increase in the WHtR, the log-ACR increased by $0.522(0.096-0.949) \mathrm{log} \mathrm{mg} / \mathrm{mmol}$ among the Hindustani-Surinamese, by 0.334 (0.047-0.622) among the African-Surinamese and by $0.356(-0.010-$ 0.721) among the Dutch. However, the interaction was not statistically significant.

Conclusions: WHtR was associated with a higher ACR among populations of Hindustani-Surinamese, AfricanSurinamese and Dutch origin. Our study seems to support global use of WHtR in relation to ACR across ethnic groups. However, although not significant, the association appeared slightly stronger among the HindustaniSurinamese than among the other ethnic groups. If confirmed, this could have implications for use of the WHtR across ethnic groups.
\end{abstract}

\section{Background}

An increased excretion of albumin in urine, often expressed as the albumin-creatinine ratio (ACR), is a risk factor for cardiovascular disease and an independent predictor of mortality in the general population [1,2]. Ethnic minorities have a greater risk of albuminuria and a higher ACR than subjects of European origin [3-6].

The higher prevalence of raised ACR and albuminuria among some ethnic groups may be related to a high

\footnotetext{
* Correspondence: i.g.vanvalkengoed@amc.uva.nl

'Department of Public Health, Academic Medical Centre, University of Amsterdam, Amsterdam, the Netherlands

Full list of author information is available at the end of the article
}

prevalence of central obesity. Several studies have demonstrated that central obesity is associated with a higher ACR and albuminuria [7-12].

Besides a high prevalence of central obesity, the risk may also be related to differences in the association of central obesity with the ACR. This association could well differ across populations of various ethnicity, for instance due to differences in fat distribution [13]. However, although one study included subjects of diverse origin, no ethnicity-specific analyses were conducted [14].

Previous studies have mostly used the waist circumference or waist-to-hip ratio as a marker of central obesity.

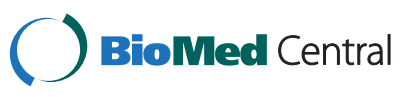


Recently, it has been suggested that the waist to height ratio (WHtR) should be used as global indicator for the health risks of obesity in (public health) practice $[15,16]$. The WHtR has been deemed a better, more sensitive measure for central obesity and is suggested to be superior for analysis of coronary risk and kidney disease [1520]. One study has directly analyzed the association of WHtR with albuminuria in a European population with type 2 diabetes [19], but did not include ethnic minority populations.

Therefore, we aimed to investigate the association between waist-to-height ratio and the ACR in a populationbased sample of 35-60 year old Hindustani-Surinamese ( South Asian), African-Surinamese ( African) and ethnic Dutch ( European) men and women, living in Amsterdam, the Netherlands. We specifically focused on potential differences in the association between ethnic groups.

\section{Methods}

\section{Study population}

The study population consisted of participants in the SUNSET study that is based on a random sample of 2975 Surinamese (i.e. with at least one parent born in Surinam) and Dutch individuals, aged 35 to 60 years of age, drawn from the Amsterdam population register [6,21]. In 1975, almost half of the population of the former Dutch colony Surinam migrated to the Netherlands. It is estimated that approximately 36\% of these immigrants were Hindustani-Surinamese (originally from the Indian subcontinent) and 41\% African-Surinamese (predominantly of African origin) [22].

Ethnicity was classified according to self-identification. If information on the self-identified ethnicity of the individual was lacking, information on the ethnic group of the mother, the father and the mother's ancestors was used to classify participants.

\section{Data collection}

Between 2001 and 2003, all subjects in the sample were approached for a face-to-face, structured interview by interviewers who had been matched by sex and origin. The interview included questions on self-identified ethnicity, migration history, demographic variables, lifestyle, and health status.

Immediately after the interview, participants were invited for a medical examination. Before the physical examination, trained physicians and research assistants verified that participants were fasting. During the examination, staff recorded: weight in light clothing on a SECA mechanical scale (SECA gmbh \& co, Hamburg, Germany) to the nearest 200 grams; height to the nearest 0.01 meter by tape measure with participants standing against a wall, heels together, feet at a 45 degree angle and head positioned in the Frankfurt plane; waist circumference midway between the lower rib margin and the iliac crest and hip circumference at the maximum point over the greater trochanters to the nearest 0.01 meter by tape measure. After the subjects had emptied their bladder and had been seated for at least 5 minutes, blood pressure and resting heart rate measurements were obtained from each subject's arm at heart level using an OMRON-M4 semi-automatic sphygmomanometer (Omron Healthcare Europe BV, Hoofddorp, the Netherlands) with an appropriate-sized cuff. All anthropometric measurements and blood pressure measurements were obtained twice and the means were used for analysis.

Fasting glucose concentrations (mmol/l; HK/Glucose-6-P dehydrogenase test; P800 analyser, Roche Diagnostics, Indianapolis, IN) were determined in samples obtained at the time of the physical examination. Finally, urinary albumin (mg/l; Jaffé method; P800 analyser, Roche Diagnostics) and creatinine concentration (mmol/l; Immune-turbidimetry; P800 analyser, Roche Diagnostics) were measured in an early morning urine sample, collected on the day of the physical examination. These measurements were carried out at the Laboratory of Clinical Chemistry of the Academic Medical Center of the University of Amsterdam.

\section{Response and participation}

The overall response to the interview was $60 \%$ (Figure 1). Participants in the interview were more likely to be female, married and living with a partner and/or children, and to live in an area with a density $<2500$ addresses $/ \mathrm{km}^{2}$. However, the differences between participants and non-participants were small and trends were similar across ethnic groups (data not shown). Of those who were eligible $(n=1626), 89 \%$ participated in the physical examination (Figure 1).

In the present analysis, we included subjects who had participated in the medical examination and had complete data on waist circumference, height, urine albumin and creatinine: 334 Hindustani-Surinamese, 589 African-Surinamese and 493 Dutch. As compared to those whose data were analyzed, those who did not undergo a physical examination or had incomplete data were similar with regard to sex, self-reported morbidity and self-rated health (data not shown).

\section{Definitions}

First, we calculated the ACR by dividing the urine albumin concentration by the creatinine concentration $(\mathrm{mg} / \mathrm{mmol})$. Due to the skewed distribution, the resulting values were log-transformed before analysis $(\log A C R)$. Because of the occurrence of albumin concentrations of $0 \mathrm{mg} / \mathrm{l}(\mathrm{n}=41)$, a constant of 0.005 was 


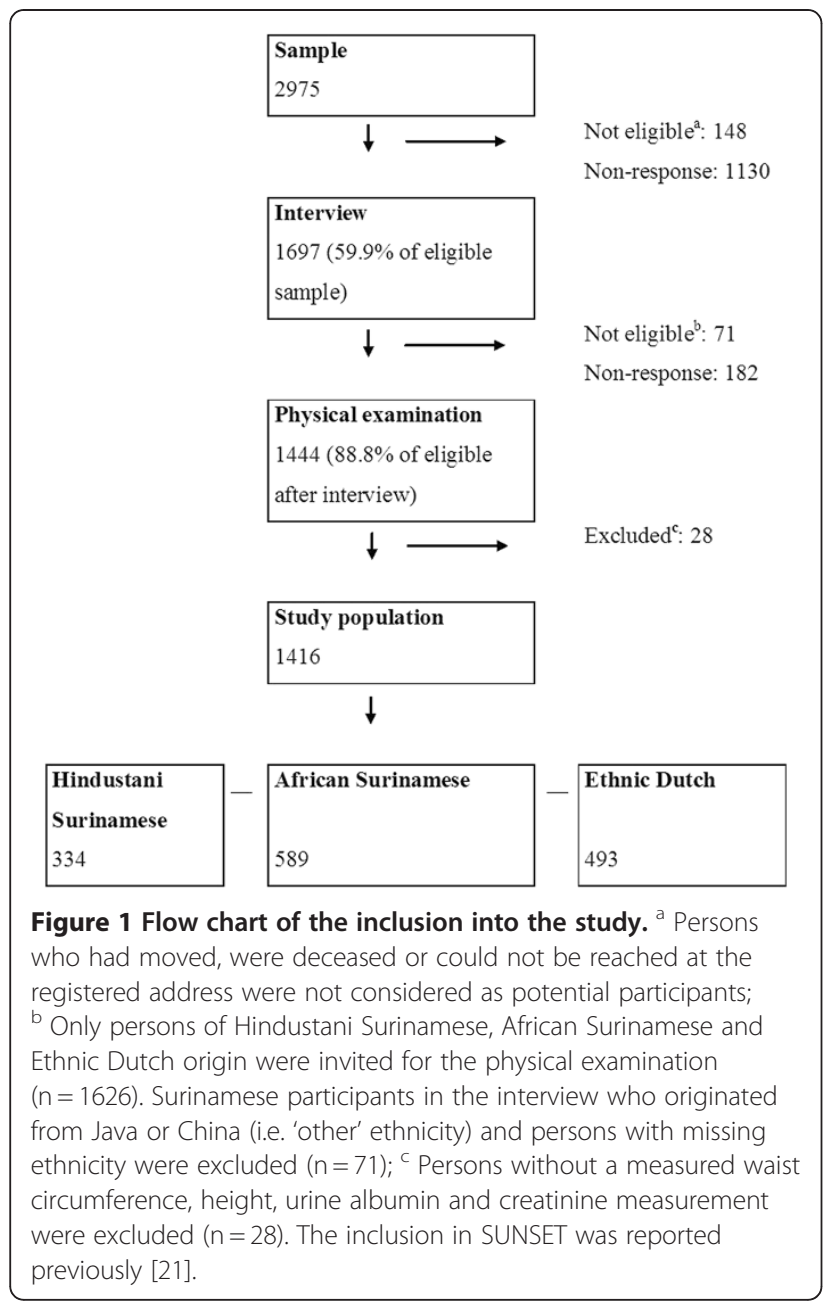

added prior to transformation and, therefore, no backtransformations could be performed. Microalbuminuria was defined as an ACR $2.5-30 \mathrm{mg} / \mathrm{mmol}$ for men and $3.5-30 \mathrm{mg} / \mathrm{mmol}$ for women and macroalbuminuria as an ACR $\geq 30 \mathrm{mg} / \mathrm{mmol}$ [23] Due to the relatively small numbers of persons with macroalbuminuria, these categories were combined for analysis.

Then, WHtR was determined by dividing the waist circumference $(\mathrm{m})$ by the measured height $(\mathrm{m})$. High WHtR was defined as a value greater than 0.50 [15].

Finally, we defined the body mass index by weight $(\mathrm{kg})$ divided by height $\left(\mathrm{m}^{2}\right)$; type 2 diabetes by fasting glucose $\geq 7.0 \mathrm{mmol} / \mathrm{l}$ and/or self-reported type 2 diabetes, excluding the self-reported diagnosis of gestational diabetes; hypertension by a $\mathrm{SBP} \geq 140 \mathrm{~mm} \mathrm{Hg}$, or $\mathrm{DBP} \geq 90$ $\mathrm{mm} \mathrm{Hg}$, or being on anti-hypertensive therapy.

\section{Statistical analyses}

Overall differences in characteristics between groups were assessed using Chi-square tests for categorical data and analysis of variance or Kruskal-Wallis tests for continuous measures. Then, post hoc tests were used to determine whether the characteristics of the Hindustani Surinamese and the African Surinamese differed from the characteristics of the Dutch.

Next, we used linear regression analysis to estimate the association between the WHtR and $\log \mathrm{ACR}$ in the total population. We adjusted for ethnicity and known determinants of ACR: sex, age, BMI, type 2 diabetes and hypertension. Moreover, we considered interaction by sex and age, as the association between body composition and chronic kidney disease has been reported to be age- and sex-dependent [24]. In addition, to verify the consistency of the associations found among subjects with and without pre-existent morbidity, we considered interaction due to the presence of hypertension or type 2 diabetes.

Subsequently, we examined the association of WHtR and $\log A C R$, stratified by ethnicity. We also tested formally for interaction between WHtR and ethnicity by adding a multiplicative interaction term to the fully adjusted model.

All analyses were performed using the SAS package, version 9.1 (SAS Institute Inc., Cary, NC). P-values $\leq 0.05$ for the likelihood ratio test ( $\leq 0.10$ for interaction), were considered statistically significant.

\section{Ethical approval}

The SUNSET-study was approved by the Institutional Review Board of the Academic Medical Center, and carried out in accordance with the Helsinki Declaration. All participants provided a written informed consent.

\section{Results}

\section{Characteristics of the study population}

Dutch participants were older and had a higher level of education than Hindustani-Surinamese and AfricanSurinamese participants (Table 1). Among men, the African Surinamese smoked more frequently than the Dutch, while among women the Hindustani Surinamese and the African Surinamese smoked less frequently than the Dutch. Among women, but not men, the Dutch more frequently complied with the guideline for physical activity than the Hindustani Surinamese. Dutch women, but not Dutch men, had a lower mean BMI than the Hindustani-Surinamese and African-Surinamese. Type 2 diabetes (in men and women) and hypertension (women only) were more prevalent among Hindustani-Surinamese and African-Surinamese than Dutch participants.

\section{Mean waist to height ratio and albumin-creatinine ratio}

The mean WHtR among Hindustani Surinamese men and women and among African Surinamese women was higher than the mean WHtR among Dutch men and women (Table 1). Hindustani-Surinamese men had the highest median ACR of 0.36 (0.20-0.91), followed by the 
Table 1 Characteristics of Hindustani-Surinamese, African-Surinamese and Dutch participants

\begin{tabular}{|c|c|c|c|}
\hline \multirow[t]{2}{*}{ Men } & \multirow[b]{2}{*}{ Hindustani-Surinamese, N = 147} & \multirow[b]{2}{*}{ African-Surinamese , N= 191} & \multirow[b]{2}{*}{ Dutch, N = 243} \\
\hline & & & \\
\hline Mean age (years) & $44.5(43.4-45.6) *$ & $44.0(43.2-44.9) *$ & $48.0(47.1-48.8)$ \\
\hline \multicolumn{4}{|l|}{ Highest level of education (\%) } \\
\hline Primary or less & $43(29.7)^{*}$ & $15(8.0)^{*}$ & $20(8.4)$ \\
\hline Secondary & $61(42.1)$ & $93(49.5)$ & $52(21.9)$ \\
\hline$\underline{\text { Lower vocational }}$ & $27(18.6)$ & $49(26.1)$ & $69(29.0)$ \\
\hline Higher vocational or more & $14(9.7)$ & 31 (16.5) & $97(40.8)$ \\
\hline Smoking (current) & $78(53.1)$ & $111(58.7)^{*}$ & $109(45.2)$ \\
\hline Physical activity (\%) & $89(60.5)$ & $107(56.0)$ & $160(65.8)$ \\
\hline Body mass index (kg/m2) & $26.4(25.5-27.2)$ & $26.3(25.7-26.9)$ & $26.2(25.7-26.8)$ \\
\hline Type 2 diabetes (\%) & $37(25.3)^{*}$ & $23(12.1)$ & $19(8.0)$ \\
\hline Hypertension (\%) & $52(36.4)$ & $81(42.9)$ & $86(35.4)$ \\
\hline Mean waist-to-height ratio & $0.56(0.55-0.57)^{*}$ & $0.52(0.51-0.53)^{*}$ & $0.53(0.52-0.54)$ \\
\hline - Waist-to-height ratio >0.50 (\%) & $117(79.6)^{*}$ & $98(51.3)^{*}$ & $155(63.8)$ \\
\hline - Mean waist circumference (m) & $0.95(0.93-0.97)$ & $0.91(0.89-0.92)^{*}$ & $0.96(0.94-0.97)$ \\
\hline - Mean height (m) & $1.70(1.69-1.71)^{*}$ & $1.75(1.74-1.76)^{*}$ & $1.80(1.79-1.81)$ \\
\hline Median ACR (mg/mmol) & $0.36(0.20-0.91)^{*}$ & $0.26(0.16-0.47)$ & $0.24(0.16-0.45)$ \\
\hline - Albuminuria (\%) & $15(10.2)$ & $11(5.8)$ & $12(5.0)$ \\
\hline Mean $\log A C R$ & $-0.70(-0.89--0.51)^{*}$ & $-1.11(-1.31--0.92)$ & $-1.34(-1.50--1.17)$ \\
\hline \multicolumn{4}{|l|}{ Women } \\
\hline & Hindustani-Surinamese, $\mathbf{N}=187$ & African-Surinamese, $\mathrm{N}=398$ & Dutch, $\mathbf{N}=\mathbf{2 5 0}$ \\
\hline Mean age (years) & $45.0(44.1-46.0)^{*}$ & $43.5(43.0-44.1)^{*}$ & $48.0(46.7-48.4)$ \\
\hline \multicolumn{4}{|l|}{ Highest level of education (\%) } \\
\hline Primary or less & $44(24.0)^{*}$ & $26(6.6)^{*}$ & $21(8.4)$ \\
\hline Secondary & $82(44.8)$ & $148(37.6)$ & $74(29.7)$ \\
\hline$\underline{L}$ Lower vocational & $39(21.3)$ & $135(34.3)$ & $71(28.5)$ \\
\hline Higher vocational or more & $18(9.8)$ & 85 (21.6) & $83(33.3)$ \\
\hline Smoking (current) & $42(22.8)^{*}$ & $124(31.7)^{*}$ & $1109(44.0)$ \\
\hline Physical activity- $\geq 30$ minutes, 5 times/week (\%) & $82(44.1)^{*}$ & $226(56.8)$ & $155(62.0)$ \\
\hline Body mass index (kg/m2) & $27.8(27.0-28.5)^{*}$ & $29.0(29.0-30.1)^{*}$ & $26.1(25.4-26.7)$ \\
\hline Type 2 diabetes (\%) & $49(26.5)^{*}$ & $51(12.9)^{*}$ & $14(5.9)$ \\
\hline Hypertension (\%) & $61(33.0)^{*}$ & $137(34.8)^{*}$ & $42(16.8)$ \\
\hline Mean waist-to-height ratio & $0.60(0.59-0.61)^{*}$ & $0.58(0.57-0.59) *$ & $0.53(0.52-0.53)$ \\
\hline - Waist-to-height ratio >0.50 (\%) & $163(87.2)^{*}$ & $323(81.2)^{*}$ & $135(54.0)$ \\
\hline - Mean waist circumference (m) & $0.94(0.92-0.96)^{*}$ & $0.95(0.94-0.97)^{*}$ & $0.88(0.86-0.90)$ \\
\hline - Mean height (m) & $1.58(1.57-1.59)^{*}$ & $1.63(1.62-1.63)^{*}$ & $1.67(1.67-1.68)$ \\
\hline Median ACR (mg/mmol) & $0.48(0.30-0.97)^{*}$ & $0.40(0.24-0.76)^{*}$ & $0.34(0.20-0.59)$ \\
\hline - Albuminuria (\%) & $13(6.9)^{*}$ & $27(6.8)^{*}$ & $4(1.6)$ \\
\hline Mean $\log A C R$ & $-0.65(-0.89--0.42)^{*}$ & $-0.70(-0.84--0.56)^{*}$ & $-1.12(-1.27--0.97)$ \\
\hline
\end{tabular}

Data are median (IQR), mean (95\%-confidence interval) or $\mathrm{N}(\%)$. Bold = difference between ethnic groups $\mathrm{p} \leq 0.05$ (Chi-square tests for categorical data and analysis of variance or Kruskal-Wallis tests for continuous measures), * Significantly different from Dutch (post hoc test) ACR =albumin-creatinine ratio, $\log A C R=\log$ albumin-creatinine ratio, Albuminuria $=A C R \quad 2.5-30 \mathrm{mg} / \mathrm{mmol}$ for men and $3.5-30 \mathrm{mg} / \mathrm{mmol}$ for women (microalbuminuria), or ACR $\geq 30 \mathrm{mg} / \mathrm{mmol}$ (macroalbuminuria). Education: Primary or less $=6$ years or less, Secondary $=10$ years, Lower vocational $=11-12$ years, Higher vocational or more $=\geq 15$ years. Physical activity $=$ at least $\geq 30$ minutes, 5 times/week.

African-Surinamese $0.26(0.16-0.47)$ and the Dutch 0.24 (0.16-0.45) $\mathrm{mg} / \mathrm{mmol}$ (Table 1$)$. The prevalence of albuminuria did not differ across the groups among men. Among women, the Hindustani-Surinamese and African-
Surinamese women had a higher median ACR than the Dutch (median ACR of 0.48 (0.30-0.97), 0.40 (0.24-0.76) and $0.34(0.20-0.59) \mathrm{mg} / \mathrm{mmol}$, respectively). A similar pattern was observed for the prevalence of albuminuria. 
Table 2 The association between waist-to-height ratio and the log albumin-creatinine ratio

\begin{tabular}{|c|c|c|c|c|c|c|c|c|}
\hline & \multicolumn{2}{|c|}{ Model 1} & \multicolumn{2}{|c|}{ Model 2} & \multicolumn{2}{|c|}{ Model 3} & \multicolumn{2}{|c|}{ Model 4} \\
\hline & Dif & $95 \%-\mathrm{Cl}$ & Dif & $95 \%-\mathrm{Cl}$ & Dif & $95 \%-\mathrm{Cl}$ & Dif & $95 \%-\mathrm{Cl}$ \\
\hline $\begin{array}{l}\text { Waist-to-height ratio } \\
\text { (per 0.1) }\end{array}$ & 0.359 & $0.278-0.440$ & 0.272 & $0.185-0.360$ & 0.451 & $0.255-0.647$ & 0.368 & $0.174-0.562$ \\
\hline $\begin{array}{l}\text { Ethnicity } \\
\text { Hindustani } \\
\text { African } \\
\text { Dutch }\end{array}$ & & & $\begin{array}{l}0.47 \\
0.35 \\
\text { Ref }\end{array}$ & $\begin{array}{l}0.28-0.67 \\
0.18-0.52\end{array}$ & $\begin{array}{l}0.41 \\
0.36 \\
\text { Ref }\end{array}$ & $\begin{array}{l}0.20-0.62 \\
0.19-0.53\end{array}$ & $\begin{array}{l}0.230 .23 \\
\text { Ref }\end{array}$ & $\begin{array}{l}0.02-0.43 \\
0.06-0.40\end{array}$ \\
\hline Sex (male) & & & -0.21 & $-0.36--0.06$ & -0.20 & $-0.35--0.06$ & -0.29 & $-0.44--0.14$ \\
\hline Age (years) & & & 0.02 & $0.01-0.03$ & 0.02 & $0.00-0.03$ & 0.00 & $-0.01-0.01$ \\
\hline Smoking (current) & & & 0.21 & $0.06-0.35$ & 0.20 & $0.05-0.35$ & 0.21 & $0.07-0.36$ \\
\hline Body mass index $(\mathrm{kg} / \mathrm{m} 2)$ & & & & & -0.03 & $-0.06-0.00$ & -0.04 & $-0.07--0.01$ \\
\hline Type 2 diabetes & & & & & & & 0.72 & $0.50-0.93$ \\
\hline Hypertension & & & & & & & 0.35 & $0.32-0.67$ \\
\hline
\end{tabular}

Dif $=$ difference, Ref $=$ reference, $\mathrm{Cl}=$ confidence interval, Bold = p-value $\leq 0.05$, Model $1=$ Unadjusted, Model $2=$ Model 1 plus ethnicity, age, sex, smoking, Model $3=$ Model 2 plus body mass index, Model $4=$ Model 3 plus type 2 diabetes, hypertension.

Association between waist-to-height ratio and logACR In the total population, the $\log A C R$ increased by 0.359 (0.278-0.440) for every 0.1 point increase in the WHtR (Table 2). The association remained similar after adjustment for sex, age, and smoking, BMI and the presence of type 2 diabetes or HT; the association was 0.368 (0.174-0.562). No significant interaction was observed for age and sex, and type 2 diabetes or hypertension (Table 3).

Among the Hindustani-Surinamese, the adjusted association between WHtR and logACR appeared stronger than among the other ethnic groups (Table 4). For every unit increase in the WHtR, the $\operatorname{logACR}$ increased by $0.522(0.096-0.949) \log \mathrm{mg} / \mathrm{mmol}$ among the Hindustani-Surinamese, by $0.334(0.047-0.622)$ among the African-Surinamese and by $0.356(-0.010-0.721)$ among the Dutch. However, the formal test for interaction provided no evidence for a differential association across ethnic groups (Table 5).

\section{Discussion}

Main findings

Central obesity, defined by the WHtR, was associated with a higher ACR among a multiethnic population of men and women aged 35-60 years. The association was consistent across sex and age groups and was not accounted for by the potentially mediating effect of preexistent morbidity.

The association seemed somewhat stronger among subjects of Hindustani-Surinamese origin than among subjects of African-Surinamese or Dutch origin, although formal testing of interaction provided no further

Table 3 Interaction between waist-to-height ratio and sex, age, type 2 diabetes, hypertension

\begin{tabular}{|c|c|c|c|c|c|}
\hline & & & Dif & $95 \%-\mathrm{Cl}$ & p-value interaction \\
\hline \multirow[t]{3}{*}{ Sex } & WHtR & (per 0.1) & 0.355 & $0.154-0.555$ & \\
\hline & Sex & (male) & -0.55 & $-1.52-0.43$ & \\
\hline & WHtR *Sex & & 0.047 & $-0.131-0.225$ & 0.60 \\
\hline \multirow[t]{3}{*}{ Age } & WHtR & & 0.729 & $0.158-1.300$ & \\
\hline & Age & (years) & 0.04 & $-0.02-0.11$ & \\
\hline & WHtR *Age & & -0.008 & $-0.020-0.004$ & 0.19 \\
\hline \multirow[t]{3}{*}{ Type 2 diabetes } & WHtR & (per 0.1) & 0.383 & $0.186-0.579$ & \\
\hline & Type 2 diabetes & & 1.45 & $0.00-2.89$ & \\
\hline & WHtR *Type 2 diabetes & & -0.120 & $-0.354-0.114$ & 0.32 \\
\hline \multirow[t]{3}{*}{ Hypertension } & WHtR & (per 0.1) & 0.334 & $0.133-0.535$ & \\
\hline & Hypertension & & -0.15 & $-1.16-0.87$ & \\
\hline & WHtR *Hypertension & & 0.115 & $-0.060-0.291$ & 0.20 \\
\hline
\end{tabular}

Dif $=$ difference, $\mathrm{Cl}=$ confidence interval, $\mathrm{WHtR}=$ waist-to-height ratio, bold $=\mathrm{p}$-value $\leq 0.05$ and $\mathrm{p} \leq 0.10$ for the interaction term, Model includes sex, age, ethnicity, smoking, body mass index, hypertension, type 2 diabetes and listed interaction term. 
Table 4 The association between waist-to-height ratio (per 0.1 ) and log albumin-creatinine ratio, stratified by ethnicity

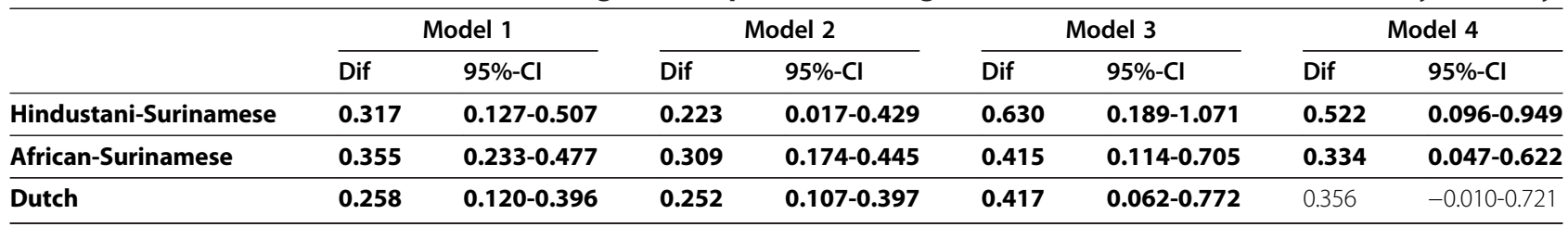

Dif $=$ difference, $\mathrm{Cl}=$ confidence interval, Bold = p-value $\leq 0.05$, Model $1=$ Unadjusted, Model $2=$ Model 1 plus age, sex, smoking, Model $3=$ Model 2 plus body mass index, Model $4=$ Model 3 plus type 2 diabetes, hypertension.

evidence for a differential association across ethnic groups.

\section{Discussion of the findings Association WHtR and $\log A C R$}

Our main finding that an increase in WHtR was associated with a higher ACR, was consistent with previous work. For instance, the association between central obesity and ACR in the Dutch men and women was in line with previous studies among populations of European origin $[9,10,25]$.

For Hindustani Surinamese, the findings were in line with a study that reported an association between waistto hip ratio and albuminuria among a South Asian population without type 2 diabetes [11]. However, the results are in contrast another study that reported the lack of a univariate association between the waist circumference and microalbuminuria among South Asian origin subjects with type 2 diabetes in India [26]. The difference between this study and our study may be related to the fact that our study also included persons without type 2 diabetes. The difference might also be related to the WHtR possibly being a more sensitive measure than waist circumference $[15,19]$. WHtR also encompasses the adjustment to different statures and thus accounts for the negative correlation of height to certain metabolic risk factors $[17,18,27,28]$.

The association between central obesity and ACR in the African Surinamese is in line with studies that showed an association between central obesity and microalbuminuria in populations of African origin, living in the US, Jamaica and South Africa [29-31].

\section{Differences in the association between ethnic groups}

No prior studies have directly compared the strength of the association between central obesity and ACR between ethnic groups. Although not statistically significant, we observed that the association between central obesity and albumin-creatinine ratio appeared slightly stronger among the Hindustani-Surinamese than among the other ethnic groups. The lack of significance may in part be related to the size of our study in combination with the fact that it was based on a relatively young and healthy general population sample. A possible difference in the association between ethnic groups is all the more striking, given that the we used the WHtR. The WHtR is recommended as a measure that can be used uniformly across different ethnic groups, including populations of Asian origin, as the division by height (in part) counteracts the higher risk associated with smaller waist circumferences in these populations [15].

Nevertheless, this measure of 'central obesity' may still reflect a very different underlying visceral versus peritoneal fat distribution. For instance, a higher amount of visceral adipose tissue, a difference in the accumulation of subcutaneous fat and a larger adipocyte size has been found among South Asians as compared to Europeans [32-34]. Additionally, the pathways through which central obesity is associated with kidney damage may also vary between the ethnic groups. For instance, a

Table 5 Interaction between waist-to-height and ethnicity in the association with log albumin-creatinine ratio

\begin{tabular}{llccc}
\hline & & Difference & $\mathbf{9 5 \% - C l}$ & p-value interaction \\
\hline WHtR & (per 0.1) & $\mathbf{0 . 3 4 0}$ & $\mathbf{0 . 1 0 7 - 0 . 5 7 3}$ & $-0.92-1.71$ \\
\hline Ethnicity & Hindustani & 0.39 & $-1.14-0.97$ \\
\cline { 2 - 4 } & African & -0.08 & & 0.70 \\
\cline { 2 - 4 } & Dutch & Ref & $-0.258-0.205$ & $-0.134-0.250$ \\
\hline WHtR*Ethnicity & Hindustani & -0.027 & \\
\cline { 2 - 4 } & African & 0.058 & \\
\cline { 2 - 5 } & Dutch & Ref & & \\
\hline
\end{tabular}

Dif = difference, Ref $=$ reference, $\mathrm{Cl}=$ confidence interval, $\mathrm{WHtR}=$ waist-to-height ratio, bold = p-value $\leq 0.05$. Model adjusted for ethnicity, age, sex, smoking, body mass index, type 2 diabetes, hypertension. 
difference in association between adiponectin, a hormone secreted by adipose tissue, and insulin resistance, a known risk factor for albuminuria, has been observed between ethnic groups [35-38]. Moreover, among South Asians, it has been suggested that the association between central obesity and insulin resistance, is not mediated by intramyocelular lipids, while it may play a role among European populations [39].

\section{Limitations}

Our study also has some limitations that should be discussed. Firstly, any associations found between WHtR and ACR have to be interpreted with caution. Due to the cross-sectional nature of the study, no causal inferences can be made.

Second, we used WHtR based on a double measurement of the waist circumference and height of participants as a marker of central obesity. This type of measure is often chosen in epidemiological studies, although several more complex methods are available to quantify central obesity, such as magnetic resonance images, computed tomography, and dual-energy X-ray absorptiometry [40-42]. However, these are relatively time-consuming and costly and thereby less suitable for epidemiological studies. Nevertheless, an imperfect marker may have led to underestimation of the associations. However, as the bias is expected to be similar across ethnic groups, the differences in the associations between groups are expected to remain.

Moreover, we used the ACR based on a single urine sample. It has been argued that the use of a single urine sample may be less accurate than a 24-hour urine collection. Nevertheless, the ACR from a single untimed specimen has been shown to correlate well with a 24-hour collection, and is more practical and less expensive than 24-hour collections for epidemiological studies [43-45].

\section{Conclusions}

We found that an increased WHtR was associated with a higher ACR among 35-60 year old men and women of South Asian, African and European origin with and without pre-existent morbidity. The WHtR is said to be a measure that suitably captures the risk associated with central obesity across ethnic groups, and our study seems to support this. However, the association with ACR appeared slightly stronger among the HindustaniSurinamese than among the other ethnic groups. This possibly differential association should be further evaluated, as it may possibly have implications for the use of the WHtR as a marker for central obesity in relation to renal outcomes in (public health) practice.

\section{Competing interests}

The author(s) declare that they have no competing interests.

\section{Author's contributions}

IGMVV designed the study, carried out the analysis, interpreted the results and wrote the first draft, CA and RTK contributed to the interpretation of the data and the revisions of the article, KS contributed to the design of the study, the interpretation and writing of the manuscript. All authors approved the final version of the manuscript.

\section{Acknowledgements}

We are very grateful to Prof. $K$ Zwinderman for his assistance with the design and the interpretation of the analysis. This study was funded by The Netherlands Organisation for Health Research and Development (ZonMw) and the Academic Medical Centre (AMC).

\section{Author details}

${ }^{1}$ Department of Public Health, Academic Medical Centre, University of Amsterdam, Amsterdam, the Netherlands. 'Division of Nephrology, Department of Internal Medicine, Academic Medical Centre, University of Amsterdam, Amsterdam, the Netherlands.

Received: 30 August 2011 Accepted: 24 April 2012

Published: 7 May 2012

\section{References}

1. Chronic Kidney Disease Prognosis Consortium: Association of estimated glomerular filtration rate and albuminuria with all-cause and cardiovascular mortality in general population cohorts: a collaborative meta-analysis. Lancet 2010, 375:2073-2081.

2. Hillege HL, Fidler V, Diercks GF, van Gilst WH, de Zeeuw D, van Veldhuisen DJ, Gans RO, Janssen WM, Grobbee DE, de Jong PE: Prevention of Renal and Vascular End Stage Disease (PREVEND) Study Group. Urinary albumin excretion predicts cardiovascular and noncardiovascular mortality in general population. Circulation 2002, 106:1777-1782

3. Fischbacher CM, Bhopal R, Rutter MK, Unwin NC, Marshall SM, White M, Alberti KG: Microalbuminuria is more frequent in South Asian than in European origin populations: a comparative study in Newcastle, UK. Diabet Med 2003, 20:31-36.

4. Bryson CL, Ross HJ, Boyko EJ, Young BA: Racial and ethnic variations in albuminuria in the US Third National Health and Nutrition Examination Survey (NHANES III) population: associations with diabetes and level of CKD. Am J Kidney Dis 2006, 48:720-726.

5. Murtaugh MA, Jacobs DR Jr, Yu X, Gross MD, Steffes M: Coronary Artery Risk Development in Young Adults Study. Correlates of urinary albumin excretion in young adult blacks and whites: the Coronary Artery Risk Development in Young Adults Study. Am J Epidemiol 2003, 158:676-686.

6. Agyemang C, van Valkengoed I, van den Born BJ, Stronks K: Prevalence of microalbuminuria and its association with pulse pressure in a multiethnic population in Amsterdam, the Netherlands - The SUNSET study. Kidney Blood Press Res 2008, 31:38-46.

7. Tamba S, Nakatsuji H, Kishida K, Noguchi M, Ogawa B, Okauchi Y, Nishizawa H, Imagawa A, Nakamura T, Matsuzawa Y, Funahashi T, Shimomura I: Relationship between visceral fat accumulation and urinary albumincreatinine ratio in middle-aged Japanese men. Atherosclerosis 2010, 211:601-605.

8. Cignarelli M, Lamacchia O: Obesity and kidney disease. Nutr Metab Cardiovas 2007, 17:757-762.

9. Liese AD, Hense H-W, Doering A, Stieber J, Keil U: Microalbuminuria, central adiposity and hypertension in the non-diabetic urban population of the MONICA Augsburg survey 1994/95. J Hum Hypertens 2001, 15:799-804.

10. Pinto-Sietsma SJ, Navis G, Janssen WMT, de Zeeuw D, Gans ROB, de Jong PE, for the PREVEND Study Group: A Central Body Fat Distribution Is Related to Renal Function Impairment, Even in Lean Subjects. Am J Kidney Dis 2003, 41:733-741.

11. Chandie Chaw PK, Berger SP, Mallat M, Froelich M, Dekker FW, Rabelink TJ: Central Obesity Is an Independent Risk Factor for Albuminuria in Nondiabetic South Asian Subjects. Diabetes Care 2007, 30:1840-1844.

12. Hanai $K$, Babazono T, Nyumura I, Toya K, Ohta M, Bouchi R, Suzuki K, Inoue A, Iwamoto $Y$ : Involvement of visceral fat in the pathogenesis of albuminuria in patients with type 2 diabetes with early stage of nephropathy. Clin Exp Nephrol 2010, 14:132-136. 
13. Carroll JF, Chiapa AL, Rodriquez M, Phelps DR, Cardarelli KM, Vishwanatha JK, Bae S, Cardarelli R: Visceral Fat, Waist Circumference, and BMI: Impact of Race/ethnicity. Obesity 2008, 16:600-607.

14. Retnakaran R, Cull CA, Thorne Kl, Adler Al, Holman RR, for the UKPDS Study Group: Risk Factors for Renal Dysfunction in Type 2 Diabetes U.K. Prospective Diabetes Study 74. Diabetes 2006, 55:1832-1839.

15. Ashwell M, Hsieh SD: Six reasons why the waist-to-height ratio is a rapid and effective global indicator for health risks of obesity and how its use could simplify the international public health message on obesity. Int J Food Sci Nutr 2005, 56:303-307.

16. Ashwell M, Browning LM: The Increasing Importance of Waist-to-Height Ratio to Assess Cardiometabolic Risk: A Plea for Consistent Terminology. Open Obes J 2011, 3:70-77.

17. Hsieh SD, Yoshinaga $\mathrm{H}$ : Abdominal fat distribution and coronary heart disease risk factors in men - waist/height ratio as a simple and useful predictor. Int J Obes Relat Metab Disord 1995, 19:585-589.

18. Hsieh SD, Yoshinaga H, Muto T: Waist-to-height ratio, a simple and practical index for assessing central fat distribution and metabolic risk in Japanese men and women. Int J Obes Relat Metab Disord 2003, 27:610-616.

19. Lamacchia O, Pinnelli S, Camarchio D, Fariello S, Gesualdo L, Stallone G, Cignarelli M: Waist-to-Height Ratio Is the Best Anthropometric Index in Association with Adverse Cardiorenal Outcomes in Type 2 Diabetes Mellitus Patients. Am J Nephrol 2009, 29:615-619.

20. Lin C-H, Chou C-Y, Lin C-C, Huang C-C, Liu C-S, Lai S-W: Waist-to-height ratio is the best index of obesity in association with chronic kidney disease. Nutrition 2007, 23:788-793.

21. Bindraban NR, van Valkengoed IG, Mairuhu G, Holleman F, Hoekstra JB, Michels BP, Koopmans RP, Stronks K: Prevalence of diabetes mellitus and the performance of a risk score among Hindustani-Surinamese, AfricanSurinamese and Dutch: a cross-sectional population-based study. BMC Public Health 2008, 8:271

22. Choenni C, Harmsen C: Place of birth and ethnic composition of the Surinamese in the Netherlands [in Dutch]. Bevolkingstrends 2007, 1:74-78.

23. Levey AS, Coresh J, Balk E, Kausz AT, Levin A, Steffes MW, Hogg RJ, Perrone RD, Lau J, Eknoyan G: National Kidney Foundation Practice Guidelines for Chronic Kidney Disease: Evaluation, Classification, and Stratification. Ann Intern Med 2003, 139:137-147.

24. Han SS, Heo NJ, Na KY, Chae DW, Kim YS, Kim S, Chin HJ: Age- and Gender-Dependent Correlations between Body Composition and Chronic Kidney Disease. Am J Nephrol 2010, 31:83-89.

25. Bonnet F, Marre M, Halimi J, Stengel B, Langed C, Laville M, Tichet J, Balkau $B$, and the DESIR Study Group: Waist circumference and the metabolic syndrome predict the development of elevated albuminuria in nondiabetic subjects: the DESIR Study. J Hypertens 2006, 24:1157-1163.

26. Unnikrishnan RI, Rema M, Pradeepa R, Deepa M, Shanthirani CS, Deepa R, Mohan $\mathrm{V}$ : Prevalence and risk factors of diabetic nephropathy in an urban South Indian population: the Chennai Urban Rural Epidemiology Study (CURES 45). Diabetes Care 2007, 30:2019-2024

27. Patel S, Unwin N, Bhopal R, White M, Harland J, Ayis SA, Watson W, Alberti KG: A comparison of proxy measures of abdominal obesity in Chinese, European and South Asian adults. Diabet Med 1999, 16:853-860

28. Henriksson KM, Lindblad U, Agren B, Nilsson-Ehle P, Rastam L: Associations between body height, body composition and cholesterol levels in middle-aged men. The coronary risk factor study in southern Sweden. CRISS. Eur J Epidemiol 2001, 17:521-526.

29. Reid M, Bennett F, Wilks R, Forrester T: Microalbuminuria, renal function and waist:hip ratio in black hypertensive Jamaicans. J Hum Hypertens 1998, 12:221-227.

30. Flessner MF, Wyatt SB, Akylbekova EL, Coady S, Fulop T, Lee F, Taylor HA, Crook E: Prevalence and awareness of CKD among African Americans: the Jackson Heart Study. Am J Kidney Dis 2009, 53:238-247.

31. Hoebel S, de Ridder JH, Malan L: The association between anthropometric parameters, the metabolic syndrome and microalbuminuria in black Africans: the SABPA study. Cardiovasc J Afr 2010, 21:148-152.

32. Lear SA, Humphries $\mathrm{KH}$, Kohli S, Birmingham $\mathrm{CL}$ : The use of BMI and waist circumference as surrogates of body fat differs by ethnicity. Obesity 2007, 15:2817-2824.

33. Lear SA, Humphries KH, Kohli S, Chockalingam A, Frohlich JJ, Birmingham $\mathrm{CL}$ : Visceral adipose tissue accumulation differs according to ethnic background: results of the Multicultural Community Health Assessment Trial (M-CHAT). Am J Clin Nutr 2007, 86:353-359.

34. Chandalia M, Lin P, Seenivasan T, Livingston EH, Snell PG, Grundy SM, Abate $\mathrm{N}$ : Insulin resistance and body fat distribution in South Asian men compared to Caucasian men. PLoS One 2007, 2:e812.

35. Carey DG, Jenkins AB, Campbell LV, Freund J, Chisholm DJ: Abdominal fat and insulin resistance in normal and overweight women. Direct measurements reveal a strong relationship in subjects at both low and high risk of NIDDM. Diabetes 1996, 45:633-638.

36. Parvanova Al, Trevisan R, lliev IP, Dimitrov BD, Vedovato M, Tiengo A, Remuzzi $G$, Ruggenenti $P$ : Insulin resistance and microalbuminuria. $A$ cross-sectional, case control study of 158 patientswith type 2 diabetes and different degrees of urinary albumin excretion. Diabetes 2006 55:1456-1462

37. Martin M, Palaniappan LP, Kwan AC, Reaven GM, Reaven PD: Ethnic differences in the relationship between adiponectin and insulin sensitivity in South Asian and Caucasian women. Diabetes Care 2008, 31:798-801.

38. Schutte AE, Huisman HW, Schutte R, Malan L, van Rooyen JM, Malan NT, Schwarz PE: Differences and similarities regarding adiponectin investigated in African and Caucasian women. Eur J Endocrinol 2007, 157:181-188.

39. Forouhi NG, Jenkinson G, Thomas EL, Mullick S, Mierisova S, Bhonsle U, McKeigue PM, Bell JD: Relation of triglyceride stores in skeletal muscle cells to central obesity and insulin sensitivity in European and South Asian men. Diabetologia 1999, 42:932-935.

40. Sobol W, Rossner S, Hinson B, Hiltbrandt E, Karstaedt N, Santago P, Wolfman $N$, Hagaman A, Crouse JR 3rd: Evaluation of a new magnetic resonance imaging method for quantitating adipose tissue areas. Int J Obes 1991, 15:589-599.

41. Tokunaga K, Matsuzawa Y, Ishikawa K, Tarui S: A novel technique for the determination of body fat by computed tomography. Int J Obes 1983, 7:437-445.

42. Stewart KJ, DeRegis JR, Turner KL, Bacher AC, Sung J, Hees PS, Shapiro EP, Tayback M, Ouyang P: Usefulness of anthropometrics and dual-energy $\mathrm{X}$ ray absorptiometry for estimating abdominal obesity measured by magnetic resonance imaging in older men and women. J Cardiopulm Rehabil 2003, 23:109-114.

43. Ginsberg JM, Chang BS, Matarese RA, Garella S: Use of single-voided urine samples to estimate quantitative proteinuria. N Engl J Med 1983, 309:1543-1546.

44. Dyer AR, Greenland P, Elliott P, Daviglus ML, Claeys G, Kesteloot H, Ueshima $\mathrm{H}$, Stamler J, INTERMAP Research Group: Evaluation of measures of urinary albumin excretion in epidemiologic studies. Am J Epidemiol 2004, 160:1122-1131.

45. Bakker AJ: Receiver operating characteristic curve analysis favors albumin-to-creatinine ratio over albumin concentration. Diabetes Care 1999, 22:307-313.

doi:10.1186/1471-2369-13-26

Cite this article as: Valkengoed et al:: Ethnic differences in the association between waist-to-height ratio and albumin-creatinine ratio: the observational SUNSET study. BMC Nephrology 2012 13:26.

\section{Submit your next manuscript to BioMed Central and take full advantage of:}

- Convenient online submission

- Thorough peer review

- No space constraints or color figure charges

- Immediate publication on acceptance

- Inclusion in PubMed, CAS, Scopus and Google Scholar

- Research which is freely available for redistribution 